\title{
Design of Star-Shaped Microstrip Patch Antenna for Ultra Wideband (UWB) Applications
}

\author{
Mustafa Abu Nasr ${ }^{1}$, Mohamed K. Ouda ${ }^{2}$ and Samer O. Ouda ${ }^{3}$ \\ ${ }^{1}$ Engineering Department, Al Azhar University, Gaza, Palestine, \\ mustafa.abunasregmail.com \\ ${ }^{2}$ Electrical Engineering Department, Islamic University of Gaza, Gaza, Palestine, \\ mouda@iugaza.edu.ps \\ ${ }^{3}$ Electrical Engineering Department, Islamic University of Gaza, Gaza, Palestine \\ s.ouda00@hotmail.com
}

\begin{abstract}
The design and analysis of a new ultra wideband microstrip antenna for optimum performance that satisfied a large bandwidth starting from $3.9 \mathrm{GHz}$ to $22.5 \mathrm{GHz}$ is introduced. The UWB antenna is capable of operating over an UWB as allocated by the Federal Communications Commission (FCC) with good radiation properties over the entire frequency range. The techniques of enhancing the bandwidth of microstrip UWB antenna were utilized to enhance the performance of the designed antenna. The effect of shifting feed line from the center of patch to the edges was studied in addition to the effect of changing the length of the ground plane. The antenna was designed and simulated using High Frequency Structure Simulator HFSS software packages..
\end{abstract}

\section{KEYWORDS}

UWB, Microstrip line feed, Patch antenna, offset feed.

\section{INTRODUCTION}

The Federal Communication Commission (FCC) specified some rules for Ultra Wideband (UWB) antenna implementations. It specified the antenna impedance bandwidth form $3.1 \mathrm{GHz}$ to 10.6 GHz and any signal that occupies at least $500 \mathrm{MHz}$ spectrum can be used in UWB systems[1]. UWB technology can be considered as the most promising wireless technologies that guarantee to provide high data rate transmissions, low complexity, very low interference and easy connection in many different devices such a laptop, digital camera, and high definition TV. Furthermore, it allows the industry to provide a greater quality of services to the end users. Highperformance printed circuit board antennas are essential in portable systems [2].The microstrip antennas are considered to be a key component for these applications due to its advantages such as, low profile, low cost, ease of integration with microwave integrated circuits (MIC) and light weight. It consists of a perfect conducting patch over a thin dielectric material called the substrate that is placed above a ground plane. There are many different patch shapes such as the rectangular, circular, elliptic, circular ring, triangular and hexagonal. There are various techniques for feeding the antenna such as microstrip line feed, coaxial probed feed, aperture-coupled and electromagnetically coupled [3]. The major disadvantages of a microstrip antennas are low power handling capability and narrow bandwidth[4]. There are continuous works for increasing the bandwidth using different techniques. One of them a technique with less complexity in structure depends on small cut on the outskirts at the upper and lower edge of patch [5]. The used of two steps at the lower edge of patch, a single horizontal rectangular slot on the patch also give good

DOI : 10.5121/ijwmn.2013.5405 
results [6]. Recently other techniques have been examined to enhance the UWB antenna using of modified shape of short ground plan. Also making multiple rectangular slots at top side of the ground plane enhances the bandwidth of antenna [7]. A larger patch with an etched slot at the lower edge of antenna with vertical slot on patch and small cut on ground plane so modified the impedance bandwidth of antenna [8]. All these techniques and others are based on the modification of the surface current destruction to enhance the antenna bandwidth.

In this paper, a microstrip star-shape antenna was studied using Ansoft's HFSS software package. HFSS is a full-wave electromagnetic simulator based on the finite element method that is considered to be the industry standard for electromagnetic and antenna simulations [9]. The antenna consists of a star-shape radiating element with a partial ground plane and a microstrip line feed from the edge of the patch. The parameters structure of the antenna was optimized to achieve the widest antenna bandwidth and impedance matching.

\section{STAR-SHAPED MICROSTRIP PATCH ANTENNA}

\subsection{Antenna Structure}

The structure and dimensions of the proposed antenna are given in Figure 1. A 50 microstrip feed line is printed on the top of "Arlon DiClad $880(\mathrm{tm})$ " substrate .The substrate has a thickness of $h=1.9 \mathrm{~mm}$ and a relative permittivity $\varepsilon_{r}=2.2, l_{s=} 25 \mathrm{~mm}$ and $w_{s}=15 \mathrm{~mm}$ denoting the length and the width of the substrate, respectively. The width of the microstrip feed line is fixed at $w_{f}$ $=4.7 \mathrm{~mm}$ to achieve 50 impedance. On the other side of the substrate, the conducting ground plane has a length of $l_{g}=7.1 \mathrm{~mm}$ and width $w_{g}$ the same of substrate width.
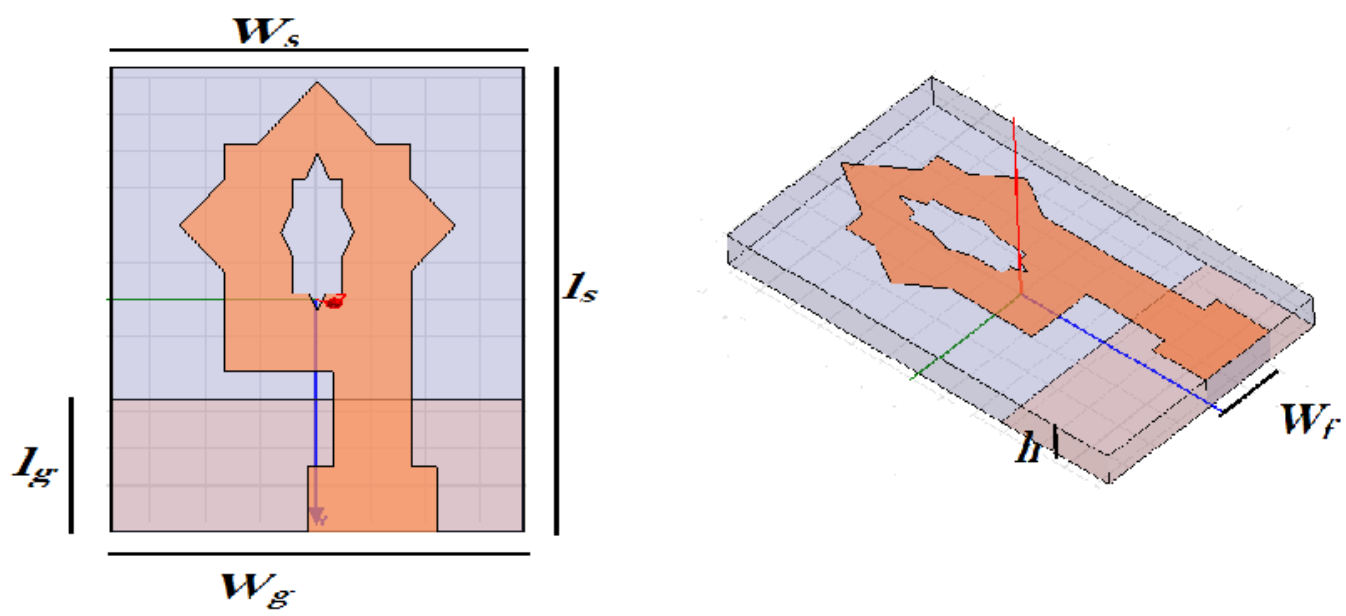

Figure 1. star shape antenna

\subsection{Result and Discussion 2.2.1 Antenna Bandwidth}

Frequency bandwidth (BW) is the range of frequencies within which the performance of the antenna, with respect to some characteristic, conforms to a specified standard. The frequency bandwidth of an antenna can be expressed as either absolute bandwidth (ABW) or fractional bandwidth (FBW) as shown in equation 1 and 2 
International Journal of Wireless \& Mobile Networks (IJWMN) Vol. 5, No. 4, August 2013

$$
\begin{aligned}
& A B W=f_{H}-f_{L} \\
& F B W=2\left(\frac{f_{H}-f_{L}}{f_{H}+f_{L}}\right)
\end{aligned}
$$

Where $f_{H}, f_{L}$ and $f_{c}$ denote the upper edge ,lower edge and center frequency respectively. For broadband antennas, the bandwidth can also be expressed as the ratio of the upper to the lower frequencies, where the antenna performance is acceptable, as shown in equation 3[1].

$$
B W=\left(\frac{f_{H}}{f_{L}}\right)
$$

The bandwidth of antenna can be considered as the range of frequencies bounded by the $\mathrm{S}_{11}$ that is lower than $-10 \mathrm{~dB}$ and it can be calculated from the $\mathrm{S}_{11}(\mathrm{~dB})$ plot [1]. Figure 2 shows that the bandwidth covering an extremely wide frequency range from $3.9 \mathrm{GHz}$ to $22.5 \mathrm{GHz}$ with a operating frequency of $10.29 \mathrm{GHz}$.

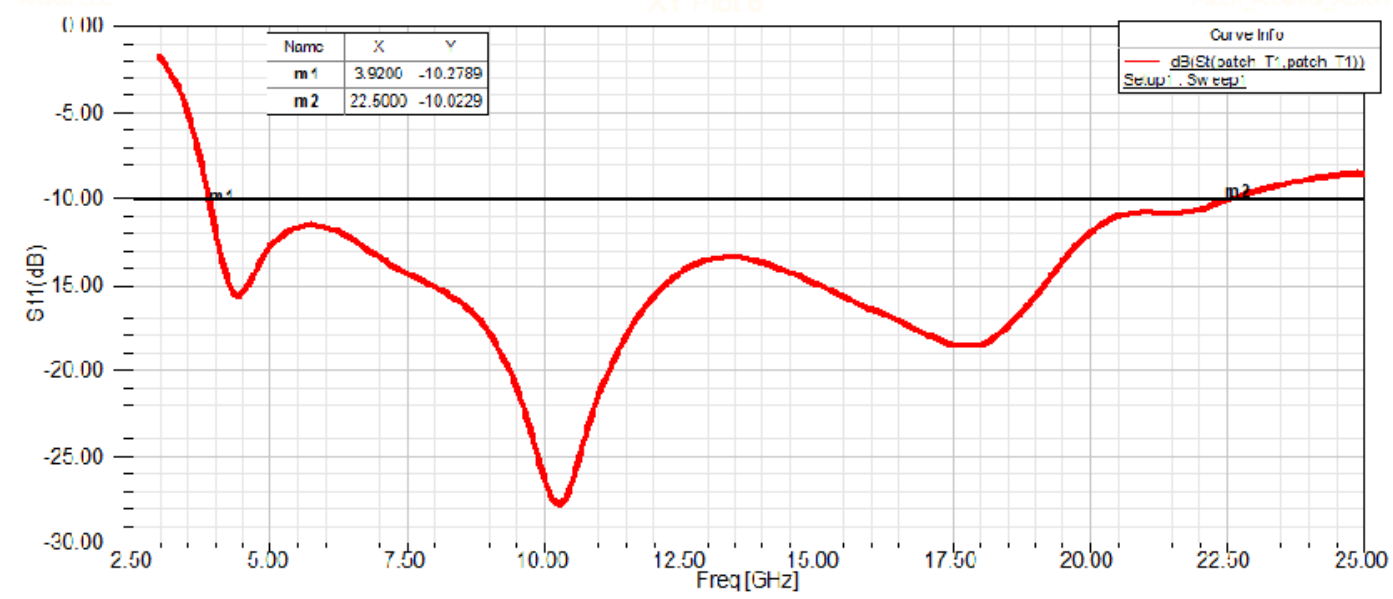

\subsubsection{Antenna Impedances}

Figure 2. $\mathrm{S}_{11}(\mathrm{~dB})$ of antenna

The microstrip transmission line feed was selected as feeding techniques for desired antenna. In this method a conducting strip connects directly to the edge of microstrip patch. The advantage of this technique comes from that layout, where the feed can be etched to same substrate to provide a planar structure [10]. The most challenge in design microstrip line is to calculate the width of line that provides good impedance matching. There is a relatively straight forward equation to calculate the characteristic impedance $Z_{0}$ given, feed line width $w_{f}$, substrate height $h$, and effective dielectric constant $\varepsilon_{\text {eff }}$ [3].

For $\frac{w}{h} \geq 1$ 


$$
\begin{aligned}
& \varepsilon_{\text {eff }}=\frac{\left(\varepsilon_{r}+1\right)}{2}+\frac{\left(\varepsilon_{r}-1\right)}{2}\left[1+12 \frac{h}{w_{f}}\right]^{-1 / 2} \\
& Z_{0}=\frac{120 \pi}{\sqrt{\varepsilon_{\text {eff }}}\left[\frac{w_{f}}{h}+1.393+0.667 \ln \left(\frac{w_{f}}{h}+1.444\right)\right]}
\end{aligned}
$$

From equation 4 and 5 we found that to achieve $50 \Omega$ characteristic impedance the $w_{f}$ is equal to $5.8 \mathrm{~mm}$, but the optimized value using HFSS software we found that $w_{f}=4.7 \mathrm{~mm}$.

Figure 3 shows the resistance and reactance behavior of the antenna as a function of frequency. It shows that the low $S_{11}(<-10 \mathrm{~dB})$ always occurs over the frequency range when the input impedance is matched to $50 \Omega$, i.e. the input resistance $R$ is close to $50 \Omega$ while the input reactance $X$ is not far from zero. At operating frequency, the resistance is closed to $50 \Omega$ and the reactance closed to 0 , thus resulting in an impedance matching at the antenna and hence increasing of the operating bandwidth.

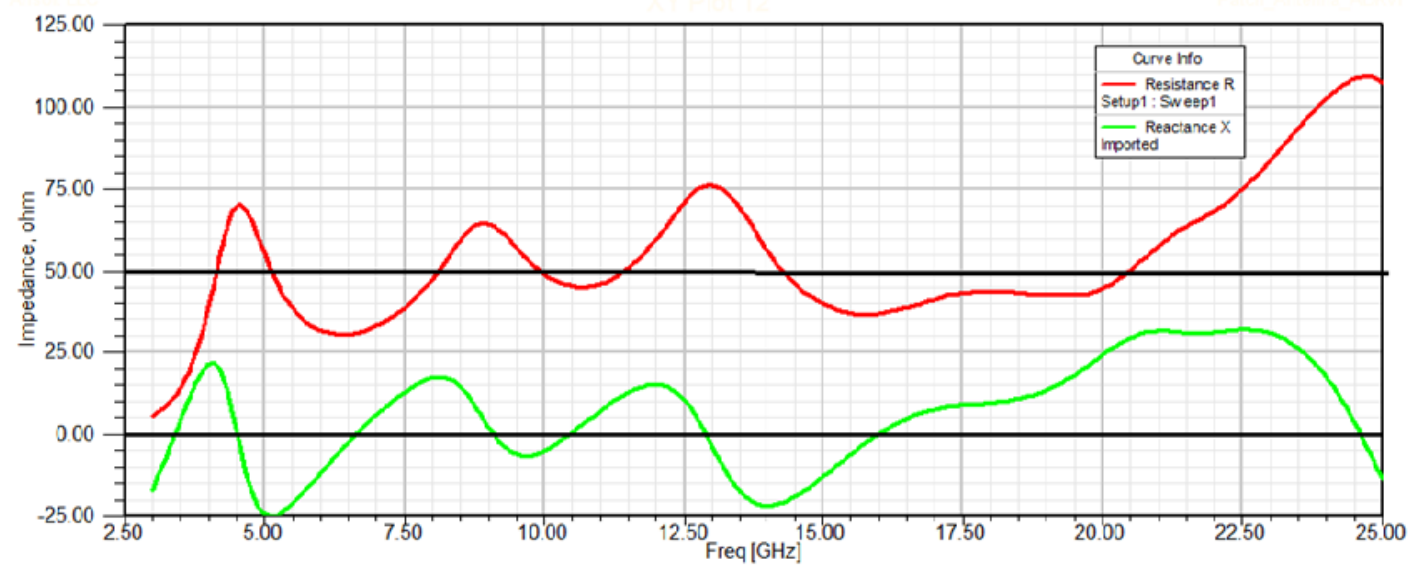

Figure 3. Resistance R and Reactance $\mathrm{X}$

\subsubsection{Antenna Gain}

The simulated of maximum gain of the optimized antenna at $\phi=0^{\circ}, 90^{\circ}$ and $\theta=0^{\circ}-180^{\circ}$ as a function of frequency is illustrated in Figure(4). It shows that at $10.29 \mathrm{GHz}$ and $17.8 \mathrm{GHz}$ frequency the gain is $4.48 \mathrm{~dB}$ and $4.4 \mathrm{~dB}$ respectively at $\phi=90^{\circ}$, but at $\phi=0^{\circ}$ the gain is $1.95 \mathrm{~dB}$ and $5 \mathrm{~dB}$ for both $10.29 \mathrm{GHz}$ and $17.8 \mathrm{GHz}$ frequency respectively. 
International Journal of Wireless \& Mobile Networks (IJWMN) Vol. 5, No. 4, August 2013

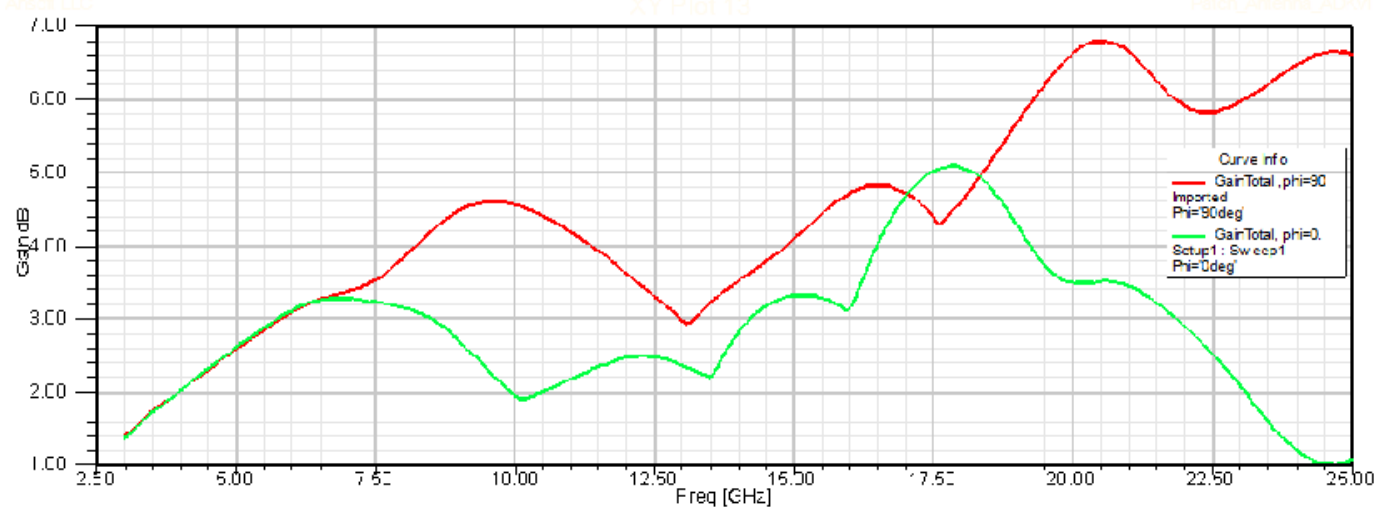

Figure 4. The simulated Gain of the antenna at $\phi=0^{\circ}, 90^{\circ}$ and $\theta=0^{\circ}-180^{\circ}$ over frequency band

\subsubsection{Antenna Radiation pattern}

Figure 5 illustrates the simulated of radiation pattern for both frequency $10.29 \mathrm{GHz}$ and $17.8 \mathrm{GHz}$ at $\phi=0^{\circ}, 90^{\circ}$ and, $\theta=0^{\circ}-180^{\circ}$

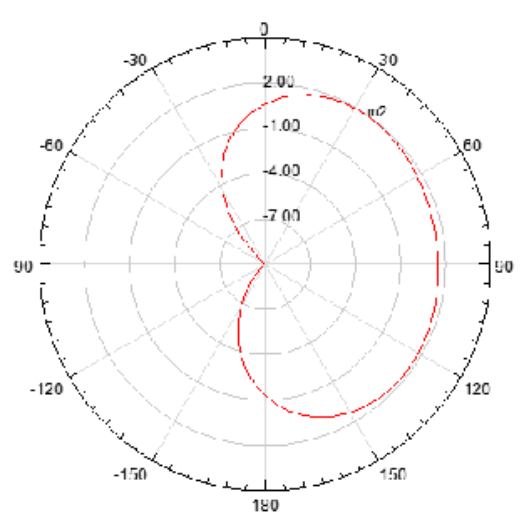

Figure5.a. radiation pattern at $10.2 \mathrm{GHz}, \phi=0^{\circ}$

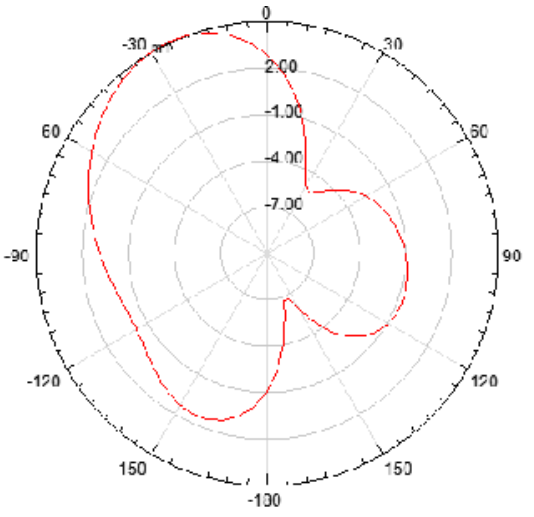

Figure 5.c. radiation pattern at $17.8 \mathrm{GHz}, \phi=0^{\circ}$

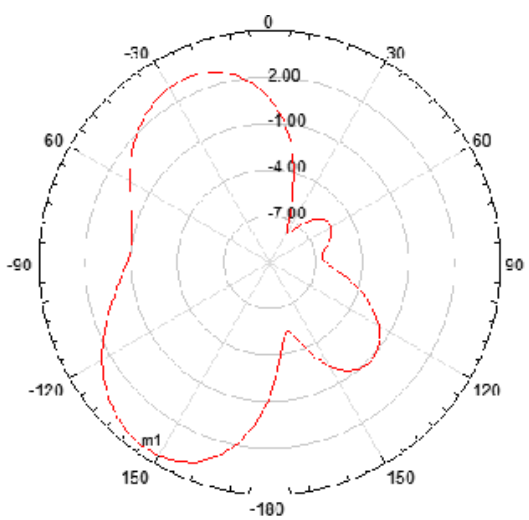

Figure5.b. radiation pattern at $10.2 \mathrm{GHz}, \phi=90^{\circ}$

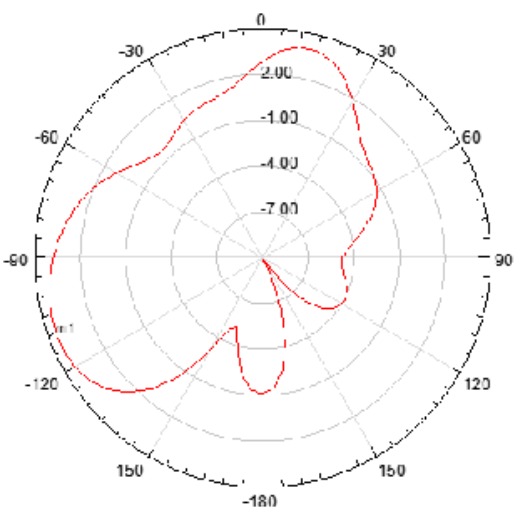

Figure 5.d. radiation pattern at $17.8 \mathrm{GHz}, \phi=90^{\circ}$ 


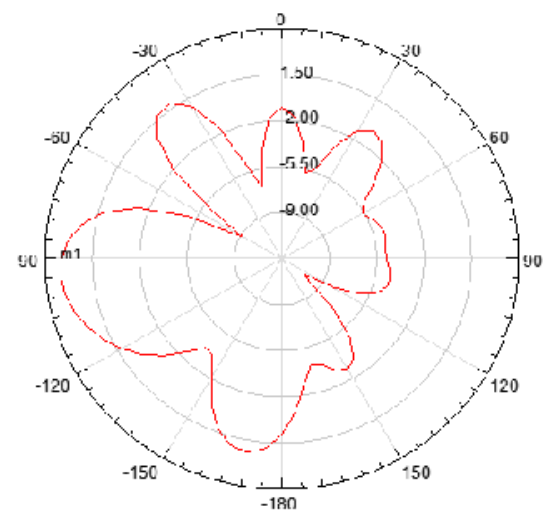

Figure5.e. radiation pattern at $17.8 \mathrm{GHz}, \theta=0^{\circ}$

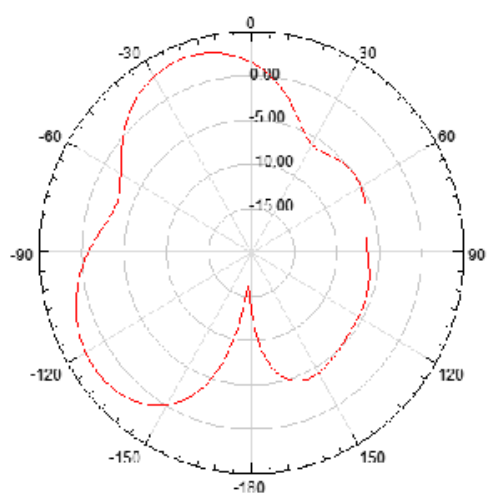

Figure 5.f. radiation pattern at $10.19 \mathrm{GHz}, \theta=90^{\circ}$

From Figure 5.a-b we can notice that the radiation pattern at $10.9 \mathrm{GHz}$ when $\phi=90^{\circ}$ is more directional compare to that at $\phi=0^{\circ}$. Also from Figure (5.c-d) it is shown that the radiation pattern at $17.8 \mathrm{GHz}$, when $\phi=0^{\circ}$ is more directional than that at $\phi=90^{\circ}$ Figure 5.e-f show the horizontal plane of radiation pattern at $\theta=90^{\circ}$.

\subsection{Parametric Study}

A parameter study was conducted to optimize antenna parameters. It helps to investigate the effect of different parameter on the impedance bandwidth. The effect of feed line shift of microstrip line and the ground plane length are studied. All the antenna parameters were kept constant in the simulation except for the parameter of interest.

\subsubsection{Effect of feed shift(Offset feed)}

Figure6 illustrates the simulated of $\mathrm{S} 11(\mathrm{~dB})$ for different feed shift steps for microstrip line feeder from the center of radiating element to its edge when the ground plan width equal to $w_{g}=15 \mathrm{~mm}$ and its length is fixed at $l_{\mathrm{g}}=7.1 \mathrm{~mm}$. Shift steps of $=0,0.4,0.8,1.2,1.6$, and $2 \mathrm{~mm}$ were simulated. 


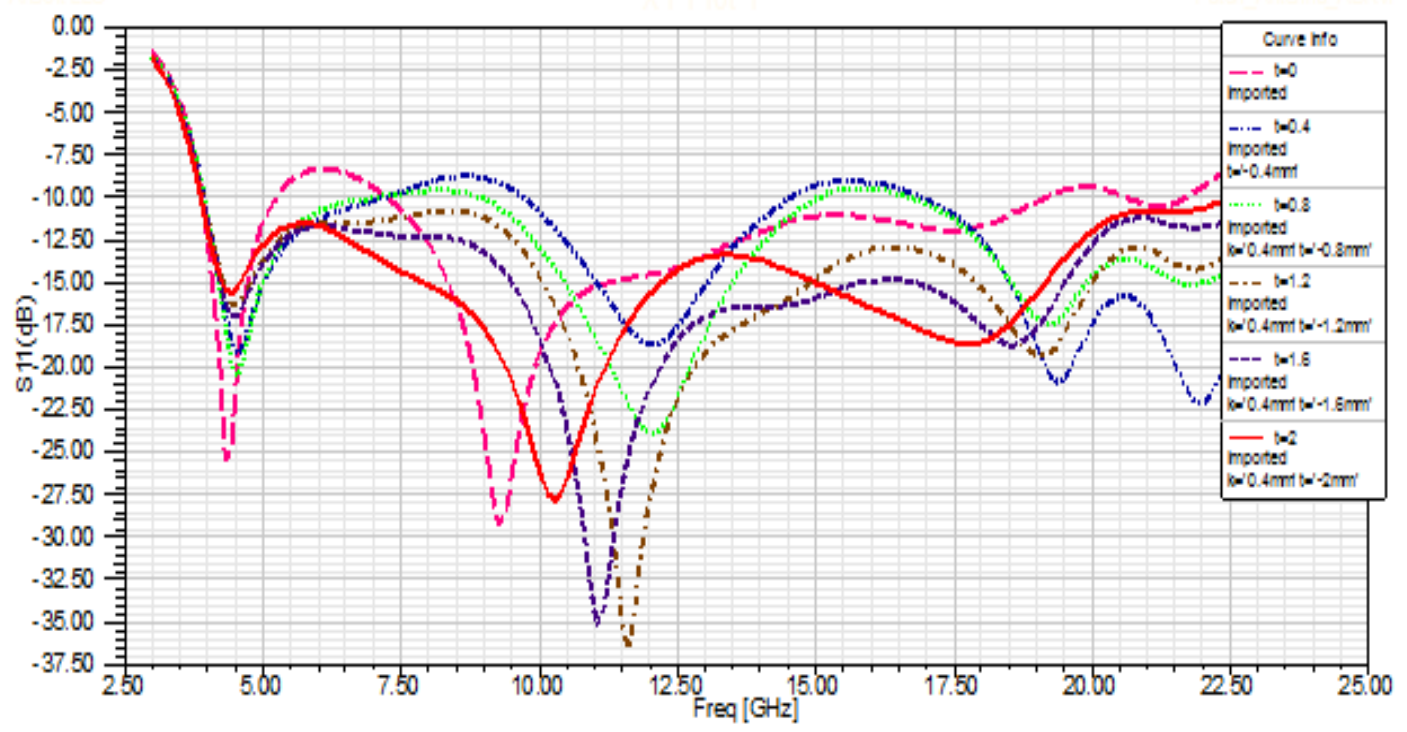

Figure 6. Simulated of $S_{11}(d B)$ curves for different feed shift

It is shown in Figure 6 that the $-10 \mathrm{~dB}$ operating bandwidth of the antenna varies remarkably with the variation of the feed shift $t$. The optimal feed shift is found to be $2 \mathrm{~mm}$ with the bandwidth covering an extremely wide frequency range from $3.9 \mathrm{GHz}$ to $22.5 \mathrm{GHz}$. The center frequency $10.29 \mathrm{GHz}$ is obtained which is very close to the desired frequency of operation. It was observed from many trials of simulations that as the feed line location is moved away from the center of the patch, the center frequency starts to decrease and the bandwidth increase.

The current distributions on the patch for each feed shift are shown in Figure 7.

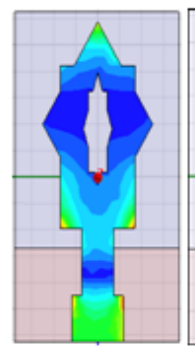

$t=0.4$

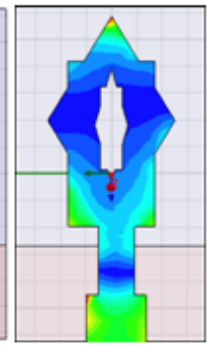

$t=0.8$

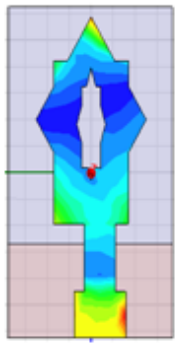

$t=0.8$

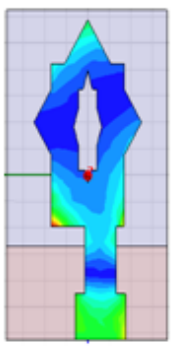

$t=1.2$

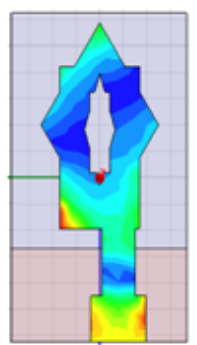

$t=0$

$t=1.6$
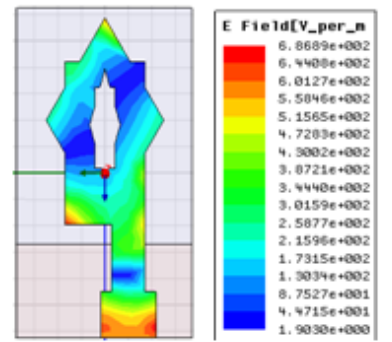

$t=2$

Figure 7. feed shift steps for microstrip-fed line with current distribution on patch 


\subsubsection{Effect of the Ground Plane}

In previous section, it has been demonstrated that the variation of the feed shift $t$ leads to the variations of the frequency bandwidth. In a broad sense, the ground plane serves as an impedance matching circuit and also it tunes the resonant frequencies [1]. To conform this, Figure 8 is given were the simulated $\mathrm{S} 11(\mathrm{~dB})$ curve for the antenna with different ground lengths $\left(l_{\mathrm{g}}=\lambda, 0.75 \lambda\right.$, $0.5 \lambda 0.25 \lambda)$.

Figure 8. Simulated of $\mathrm{S}_{11}(\mathrm{~dB})$ curve for different ground plan length

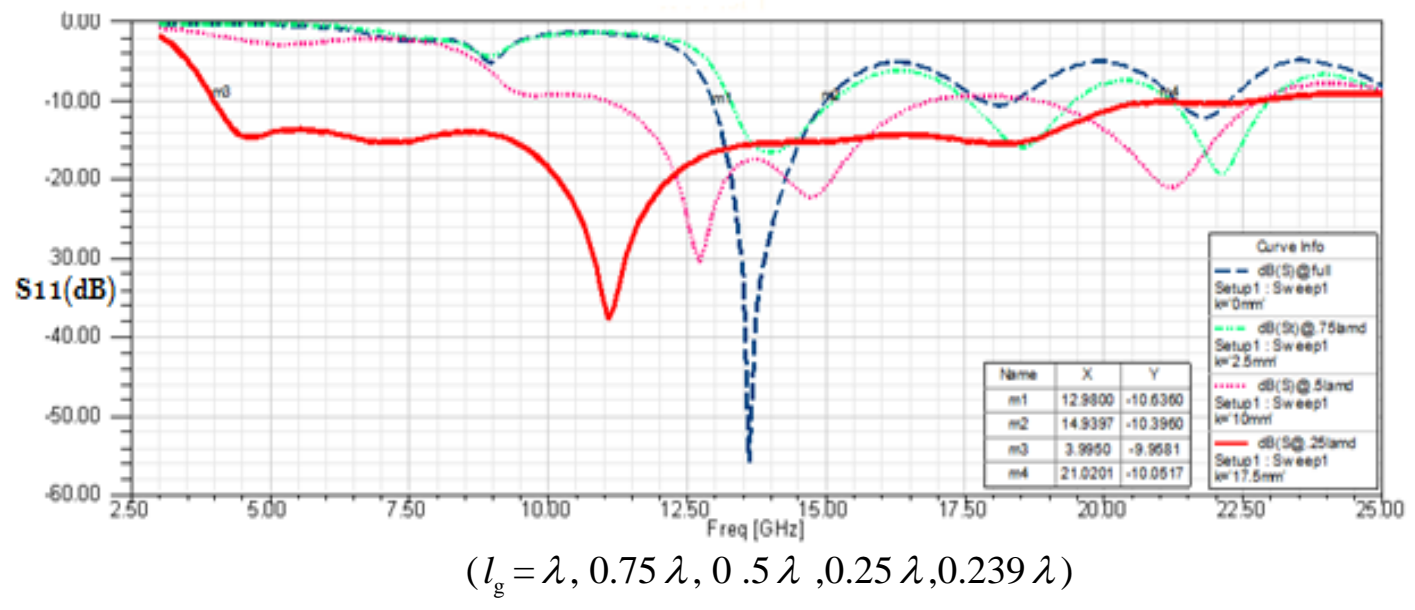

It is noticed in Figure 8 that for full ground plan the first-10dB bandwidth ranges from $12.9 \mathrm{GHz}$ to $14.9 \mathrm{GHz}$, which is much narrower than that of a short ground plane. This is due to the impedance mismatch over an extremely frequency range resulting from the full ground plane. When the length of ground plane starts to decrease, $l_{g}=0.75 \lambda, 0.5 \lambda$ we see that the bandwidth range starts to increase gradually and the $\mathrm{S} 11$ under $-10 \mathrm{~dB}$ curve becomes wider at $l_{g}$ $=0.25 \lambda$ bandwidth start from $3.9 \mathrm{GHz}$ to $21 . \mathrm{GHz}$. The optimum values was found by optimizing the antenna is $l_{g}=0.239 \lambda=7.1 \mathrm{~mm}$ were the bandwidth ranges from $3.9 \mathrm{GHz}$ to $22.5 \mathrm{GHz}$ with little frequency shift. Table 1 shows the value of the bandwidth at different length of the ground plane 
International Journal of Wireless \& Mobile Networks (IJWMN) Vol. 5, No. 4, August 2013

\begin{tabular}{|l|l|l|l|}
\hline$l_{\mathrm{g}}$ & $\begin{array}{l}\text { Start frequency } \\
\mathrm{GHz}\end{array}$ & End frequency $\mathrm{GHz}$ & Bandwidth $\mathrm{GHz}$ \\
\hline$\lambda$ & 12.9 & 14.9 & 2 \\
\hline $0.75^{\lambda}$ & 13.3 & 14.9 & 1.6 \\
\hline $0.5 \lambda$ & 11 & 17.5 & 6.5 \\
\hline $0.25 \lambda$ & 3.9 & 21 & 17.1 \\
\hline $0.239 \lambda$ & 3.9 & 22.5 & 18.6 \\
\hline
\end{tabular}

Table 1. The value of bandwidth at different length of ground plane

\section{CONCLUSION}

In this paper, a design of new microstrip UWB antenna with good performance was proposed. The antenna was designed and simulated using Ansoft's HFSS electromagnetic simulation package. The effects of feeding shift technique and the truncation of the ground plan method were studied. Enhance the antenna performance parameters was achieved. An extreme antenna bandwidth of $18.6 \mathrm{GHz}$ was achieved using ground plan $7.1 \mathrm{~mm}$.

\section{REFERENCES}

[1] Jianxin Liang(2006) Antenna Study and Design for Ultra Wideband Communication Applications, a thesis submitted of Doctor of Philosophy, University of London, United Kingdom,

[2] XiulongBao, Max Ammann: Printed band-rejection UWB antenna with H-shaped slot,Dublin Institute of Technology, 2007-01-01.

[3] Constantine A. Balanis(2005) Antenna theory analysis and design, Wiley \& Sons, Inc , third edition, Canada.

[4] David R. Jackson: Antenna Engineering Handbook, University of Houston

[5] M. Y. Alhefnawy, Aladdin Assisi, HosnyAlmotaafy, A. Safwat and M.I. Youssef (2009) "Design and Implementation of a Novel Planer UWB Monopole Antenna for Multipath Environments" ,13th International Conference on Aerospace Sciences\& Aviation Technology, ASAT.

[6] Seok H. Choi, Jong K. Park, Sun K. Kim, and Jae Y. Park, 4 August 2003: A new ultra wide band antenna for UWB application, Department of Radio Wave, Engineering Hanbat National University.

[7] Mohammed tariqual ,rezaualazim ,norbahian misran ,kamarulzaman mat ,and badrainbais(2010)" Design and optimization printed rectangular antenna for UWB application", World applied sciences .

[8] Lee Chia Ping, Chandan Kumar Chakrabarty andRozanah Amir Khan,(2010) "Enhanced Bandwidth of Impulse-Ultra Wideband (I-UWB) Slotted Rectangular Patch Antenna with Partial Ground Plane" IJECCT.

[9] Ansoft Corporation, user's guide: High Frequency Structure Simulator V10.

[10] Yogesh K. Choukiker, (2009)" Analysis of dual band rectangular microstrip antenna using IE3D/PSO", Master of technology in Telematics and signal processing, National Institute of Technology, 2009 